\title{
The Effect of Cooling Slope on Mechanical Properties of Aluminum-8.5wt.\% Si Alloy Produced by Gravity Casting
}

\author{
Tugiman $^{1 *}$, Awaluddin Thayab ${ }^{1}$, Farida Ariani ${ }^{1}$, Tulus B. Sitorus ${ }^{1}$, Suhandi $^{1}$, Rizki $^{1}$ \\ \{* tugiman.karmani@gmail.com $\}$ \\ Mechanical Engineering Department, Faculty of Engineering. University of Sumatera Utara ${ }^{1}$
}

\begin{abstract}
Cooling slopes (CS) are the novel technique in the casting process, it suitable applied in the various alloys to modify the microstructure and mechanical properties. In the present work, the cooling slope has been designed and applied in the aluminumsilicon alloys. The effect of CS plate angle on microstructure and mechanical properties of aluminum alloy were investigated. The results suggested that the CS influenced the morphologies of materials which is correspond with the mechanical properties change.
\end{abstract}

Keywords: Aluminum-Si alloy, Sloping plate, Microstructure, Hardness

\section{Introduction}

The casting processes are widely used in the engineering field to produces aluminum alloys and metal matrix composites due to their low cost in production and easy to operated. The main problem of components that produced by casting processes has poor mechanical properties; such as tensile strength and toughness. Which is, these properties are very important as one of consideration in the material selection process. Many investigated have been done to improve the mechanical properties of cast materials, the addition of reinforced $\mathrm{SiC}$ particles in aluminum matrix composites [1], pofa particles [2], and modification of microstructure by using grain refinement agents such Al-Ti and Al-Ti-B master alloys [3] are influence the mechanical properties of aluminum alloys. Besides the techniques above, recently, many researchers have developed the cooling slope system to improve the mechanical properties of casting materials. T.Haga et al [4] observed that casting factors such as nozzle size, height nozzle, tilt, and slope length influenced the semisolid slurry of the A356 aluminum alloy. The spherical microstructure of semi-solid slurry primary Al phase was observed in this alloy produced by cooling slope [5]. Besides the shapes grain, the size is important to determine the mechanical properties. Further, this technique can be used to reduce the grain size aluminum alloy [6] through slurry formation before flows into the permanent mold.

The cooling slope method was applied in various alloy system such A356 [4,5], AlSi7Mg [7] and AA 7075 wrougth aluminum alloy [8]. From previous research shown that this technique was successful to modify a microstructure and mechanical properties of $\mathrm{Al}$ alloys, however, aluminum-8.5Si alloy produced by this technique is only a few. Based on this fact, in the present work discuss the effect of the cooling slope angle on microstructures and mechanical properties. 


\section{Methodology}

In the present research, the Aluminum A356 ingots are used as a matrix with the main element alloy consist of $\mathrm{Si}, \mathrm{Fe}$, and Ti respectively see table 1.

Table 1. The chemical composition of aluminum ingot used in the present work

\begin{tabular}{lllllllllll}
\hline Elements & $\mathrm{Si}$ & $\mathrm{Fe}$ & $\mathrm{Cu}$ & $\mathrm{Mn}$ & $\mathrm{Mg}$ & $\mathrm{Cr}$ & $\mathrm{Ni}$ & $\mathrm{Zn}$ & $\mathrm{Ti}$ & $\mathrm{Al}$ \\
\hline wt.\% & 8.5 & 0.18 & 0.003 & 0.004 & 0.074 & 0.0007 & 0.002 & 0.004 & 0.159 & bal. \\
\hline
\end{tabular}

The aluminum-silicon ingot has been melted by using conventional furnace, aluminum alloy was remelted in a graphite crucible with pouring temperature at $680 \mathrm{C}$. Cooling slope plate made from mild steel with $300 \mathrm{~mm}$ length as shown in fig. 1, the cooling slope angles were varied at $15^{\circ}, 30^{\circ}, 45^{\circ}, 60^{\circ}$ and $75^{\circ}$ with respect to the horizontal plane. This plate equipped with a cooling system, water cooling media used to control temperature on the bottom surface of an inclined plate. The molten aluminum flowing on the plate surface cause sticking phenomenon. Boron nitride coating method used to prevent this phenomenon. The cylindrical permanent mold used in the present work made from mild steel with $80 \mathrm{~mm}$ inside diameter and $100 \mathrm{~mm}$ height. Further, aluminum melt flow filling the permanent mold followed by cool down to room temperature. The microstructures from bottom region samples were examined by using an optical microscope, metallographic investigation obtained without etched process on the specimens. Brinnel hardness test has been done with $500 \mathrm{~kg}$ load for 15 seconds in bottom area. Further, the Charpy method with $251.3 \mathrm{~N}$ of the load used to measure the impact strength and tensile test by using a universal testing machine to investigate the strength of materials at room temperature. The aluminum castings from the bottom and top area were selected for both of testing.

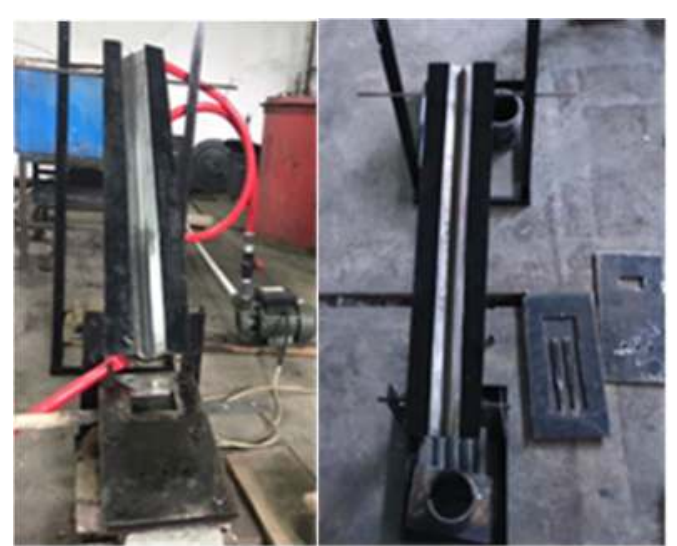

Fig. 1. Schematic cooling slope facility 


\section{Result and Discussion}

\subsection{Microstructures}
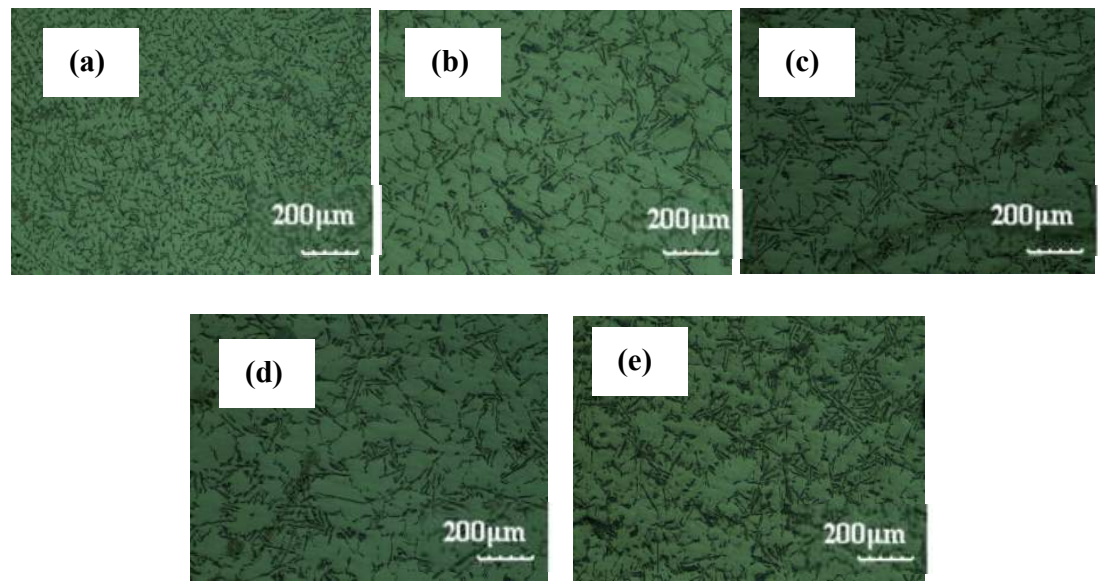

Fig. 2. shows the microstructure of alumunium alloy in various tilt angle (a) 15, (b) 30, (c) 45, (d) 60 and (e) 750

Figure 2 shows the microstructures re-casting aluminum-silicon alloy which produced by cooling slope method with varying tilt angle. The microstructure visible consist of two main regions i.e. dark color identified as Si-rich dispersed between $\square$-Al dendrites with bright color. Figure 2 a shows the microstructure aluminum-silicon alloy with $15^{\circ}$ inclined, the small $\square$-Al grain with dimension less $50 \mu \mathrm{m}$ in diameter was obtained. Figure $\mathbf{2 b}$-e shows the dimension of $\square$-Al dendrites enlarged correspond with the increased inclined plate of cooling slope. Aluminum melt poured onto a high inclined plate is easier flowing down to fill the permanent mold. The sluggish solidification rate in the permanent mold compared with on the cooling slope surface, which is the microstructures and grain of aluminum influenced by solidification rate [9]. Solidification mechanism is important parameters in the grain growth process. R. Ritwik, et al., (2013) [7] observed that the microstructures influenced by the nucleation and growth mechanism.

Figure 2e shows the microstructure aluminum-silicon alloy particles consist of $\square$-Al dendrites with more than $200 \mu \mathrm{m}$ length, in other side, most of Al-silicone eutectic elements dispersed between aluminum matrix. Silicone particles (dark area) has higher melting point than aluminum, it is one of the reasons in room temperature these particles are hard to form solid solutions with aluminum.
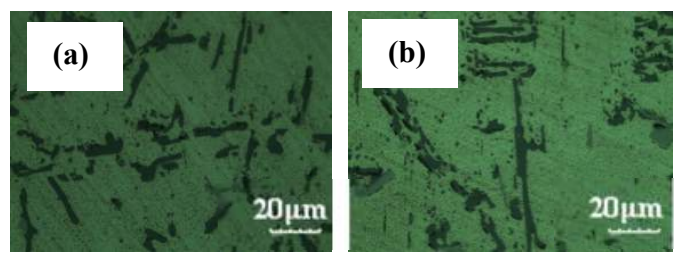

Fig. 3. shows the microstructure of aluminum-silicon alloy in the various tilt angle (a) 15 and (e) 750. 
Figure 3a shows the microstructure recasting of aluminum-silicon alloy produced by $15^{\circ}$ inclined plate, visible the eutectic silicon distributed with small size and more homogeneous. Figure 3b shows the distribution of silicone particles (dark area) at tilt angle $75^{\circ}$, the particles dispersed with clusters and longitudinal shape. The distribution and dimension of the silicon particles in the aluminum matrix are important alter the properties of alloy.

\subsection{The mechanical properties}

Figure 4 shows the hardness of aluminum-silicon alloy in a various inclined plate of the cooling slope. The maximum hardness $60.7 \mathrm{BHN}$ was obtained at the low angle plate $15^{\circ}$. The increase of angle causes the hardness slightly decrease until $49 \mathrm{BHN}$ at $75^{\circ}$.

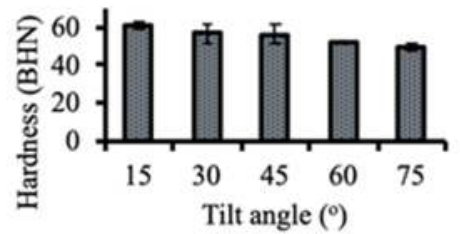

Fig. 4. Hardness of aluminium-silicon alloy in various tilt angle of the cooling slope.

The hardness of aluminum alloys slightly decreased along with the increase of tilt angle due to more flow rate of aluminum filling the permanent mold cavity. It is believed that the more heat transfer rate on the plate surface because of direct contact with the air than the inside of the permanent mold. The slow heat transfer between the aluminum melt and wall mold cause the grain growth process occurred. In the present work, the lower hardness obtained due to the bigger $\square$-Al grain formed with high tilt angle, see Figure 2e.

Figure 5 shows the effect of slope angle of cooling slope on the impact strength of aluminum-silicon alloy in various tilt angle from 15 to $75^{\circ}$.

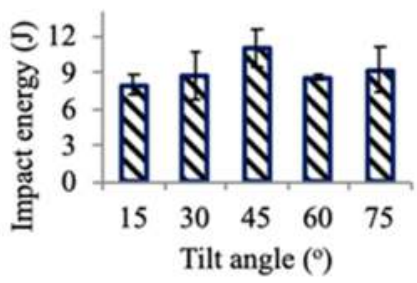

Fig. 5. The Impact resistance of aluminium-silicon alloy in various tilt angle of cooling slope.

The impact strength at $15^{\circ}$ angle about 8 Joules, this value increased along with the increase of tilt angle until $45^{\circ}$ about 12 Joules. Furthermore, the increase of tilt angle tends to reduce the impact energy until $75^{\circ}$. The impact strength between the bottom and top region of the aluminum castings are different, it can be identified that standard deviation several samples higher than others. It is believed that the impact strength of casting materials influenced by many factors such as pouring temperature [10], porosity, defect, and microstructure morphology. Figure 5 shows that the impact strength is low and close to each other, this corresponds with the fracture surface (see Figure 6) of samples which is the surface visible with bright color, flat without stringy. 

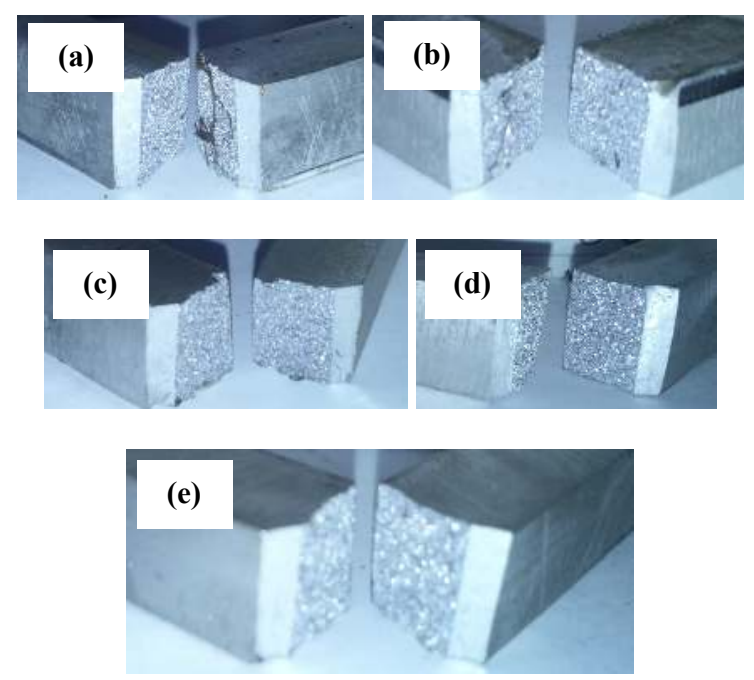

Fig. 6. Fracture surface of impact test for various tilt angle of cooling slope (a) 15, (b) 30, (c) 45, (d) 60 and (e) $75^{\circ}$.

Figure 7 shows the ultimate tensile strength of aluminum-Si alloy re-casting by cooling slope method with different tilt angle. The maximum ultimate tensile strength $135 \mathrm{MPa}$ obtained at $45^{\circ}$ inclined. The tensile strength of Al-Si alloy as shown as in Figure 7 tend to low compared with the standard specimen of aluminum A356 alloys. The tensile strength aluminum alloys decrease due to casting defects such cold flakes [11], porosity [12]. The present work obtained porosity inside of cast material cause deterioration tensile strength. Furthermore, the fracturing usually occurred in the area with a high concentration of porosity [12].

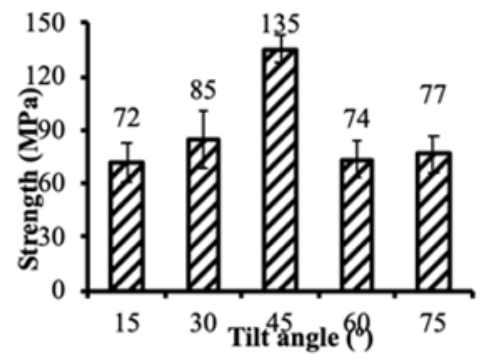

Fig. 7. The ultimate tensile strength of alloy in various tilt angle of cooling slope.
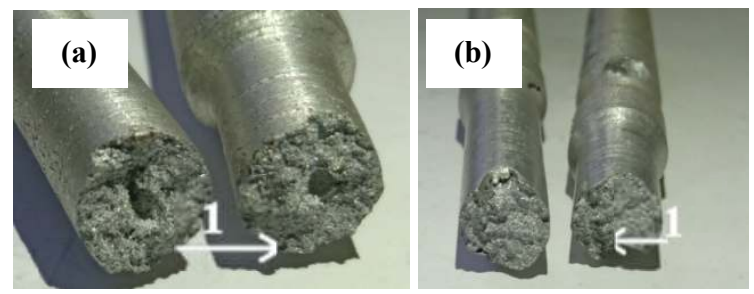

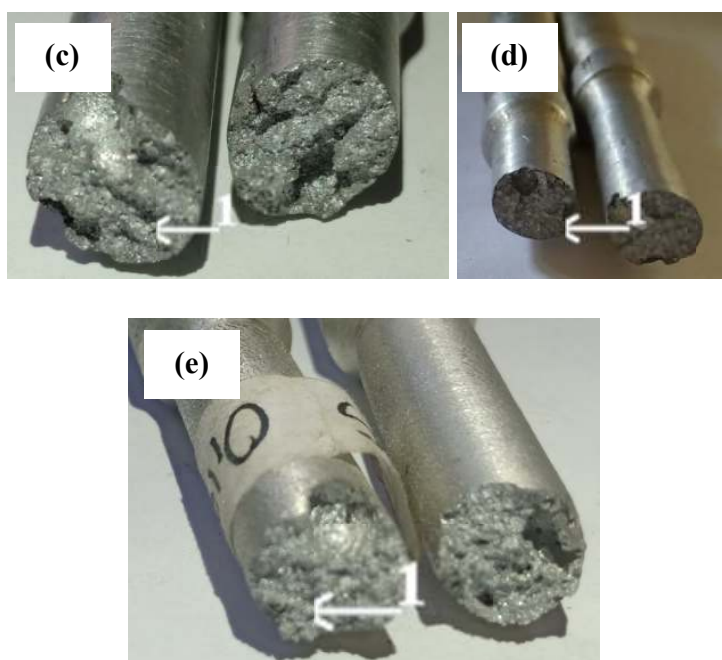

Fig. 8. Fracture surface of tensile materilas in various tilt angle (a) 15, (b) 30, (c) 45, (d) 60 and (e) $75^{\circ}$.

Figure 8 shows the surface fracture morphology of tensile test samples, the casting defects found in almost all specimen. The internal defect such porosity with different size found in many areas of samples see Figure. 8 (arrow no.1). The defects such as gas porosity and blowhole are a usual defect found in the materials produced by casting process [13]. The existence of porosity inside an aluminum castings influence to mechanical properties and yield strength [12]. Figure. 8 shows the surface visible flat with a little dark area and diameter of specimens are looks like the same size near fracture area, based on this characteristic can be drawn an assumption that samples have low elongation.

\section{Conclusion}

Based on the data of microstructures and mechanical properties can be drawn several points in the present work:

a. Cooling slope method was successful to produce Al-Si alloy cast with the different tilt angle.

b. The tilt angle of cooling slope influences the microstructure and mechanical properties of aluminum-silicon alloy.

c. Re-casting aluminum-silicon alloy by using gravity casting obtained different mechanical properties with a different cast area.

d. The mechanical properties such as impact and tensile strength are strongly influenced by casting defect, low mechanical properties obtained due to more porosity formed in microstructures.

\section{References}

[1] D. D. Wacono et al., "PENGARUH PERSENTASE BERAT SERBUK SiC TERHADAP SIFAT FISIK DAN SIFAT MEKANIK KOMPOSIT DENGAN MATRIK AISiTiB YANG DIPERKUAT SERBUK SiC 1 *,” vol. 2, no. 3, pp. 239-248, 2014. 
[2] Tugiman, F. Ariani, F. Taher, M. S. Hasibuan, and Suprianto, "The analysis of composite properties reinforced with particles from palm oil industry waste produced by casting methods," IOP Conf. Ser. Mater. Sci. Eng., vol. 277, no. 1, 2017.

[3] K. T. Kashyap and T. Chandrashekar, "Effects and mechanisms of grain refinement in aluminium alloys," Bull. Mater. Sci., vol. 24, no. 4, pp. 345-353, 2001.

[4] T. Haga, R. Nakamura, R. Tago, and H. Watari, "Effects of casting factors of cooling slope on semisolid condition," Trans. Nonferrous Met. Soc. China (English Ed., vol. 20, no. SUPPL. 3, pp. s968-s972, 2010.

[5] P. Das, S. K. Samanta, B. R. K. Venkatpathi, H. Chattopadhyay, and P. Dutta, "Microstructural evolution of A356 Al alloy during flow along a cooling slope," Trans. Indian Inst. Met., vol. 65 , no. 6, pp. 669-672, 2012.

[6] A. Mehmood, M. Shah, N. A. Sheikh, J. A. Qayyum, and S. Khushnood, "Grain refinement of ASTM A356 aluminum alloy using sloping plate process through gravity die casting," Alexandria Eng. J., vol. 55, no. 3, pp. 2431-2438, 2016.

[7] R. Ritwik, A. K. Prasada Rao, and B. K. Dhindaw, "Low-convection-cooling slope cast AlSi7Mg alloy: A rheological perspective," J. Mater. Eng. Perform., vol. 22, no. 9, pp. 2487 2492,2013

[8] A. M. E.Y.El-Kady, I.S.El-Mahallawi, T.S.Mahmoud, A.Attia, S.S.Mohanned, "Optimization of the cooling slope casting parameters for producing aa7075 wrought aluminum alloy thixotropic feedstock," Mater. Sci. an Indian J., vol. 14, no. 8, pp. 279-287, 2016.

[9] S. Liu et al., "Effect of Cooling Rate on Microstructure and Grain Refining Behavior of In Situ CeB6/Al Composite Inoculant in Aluminum," Metals (Basel)., vol. 7, no. 6, p. 204, 2017.

[10] S. O. Adeosun, E. I. A. $\Psi$, and P. I. Odetola, "Pouring Temperature Effects on Mechanical and Electrical Responses of Cast 6063 Aluminum Alloy," vol. 41, no. 1, pp. 4-10, 2013.

[11] A. K. M. A. Ahamed and H. Kato, "Influence of Casting Defects on Tensile Properties of ADC12 Aluminum Alloy Die-Castings," Mater. Trans., vol. 49, no. 7, pp. 1621-1628, 2008.

[12] G. W. Mugica, D. O. Tovio, J. C. Cuyas, and A. C. González, "Effect of Porosity on the Tensile Properties of Low Ductility Aluminum Alloys," Mater. Res., vol. 7, no. 2, pp. $221-$ 229, 2004.

[13] R. Rajkolhe and J. G. Khan, "Defects , Causes and Their Remedies in Casting Process : A Review," Int. J. Res. Advent Technol., vol. 2, no. 3, pp. 375-383, 2014. 